\title{
Bipolar Cells Contribute to Nonlinear Spatial Summation in the Brisk-Transient (Y) Ganglion Cell in Mammalian Retina
}

\author{
Jonathan B. Demb,, ${ }^{1}$ Kareem Zaghloul, ${ }^{1}$ Loren Haarsma, ${ }^{1,2}$ and Peter Sterling ${ }^{1}$ \\ ${ }^{1}$ Department of Neuroscience, University of Pennsylvania School of Medicine, Philadelphia, Pennsylvania 19104-6058, \\ and ${ }^{2}$ Department of Physics and Astronomy, Calvin College, Grand Rapids, Michigan 49546
}

\begin{abstract}
The receptive field of the Y-ganglion cell comprises two excitatory mechanisms: one integrates linearly over a narrow field, and the other integrates nonlinearly over a wide field. The linear mechanism has been attributed to input from bipolar cells, and the nonlinear mechanism has been attributed to input from a class of amacrine cells whose nonlinear "subunits" extend across the linear receptive field and beyond. However, the central component of the nonlinear mechanism could in theory be driven by bipolar input if that input were rectified. Recording intracellularly from the Y-cell in guinea pig retina, we blocked the peripheral component of the nonlinear mechanism with
\end{abstract}

tetrodotoxin and found the remaining nonlinear receptive field to be precisely co-spatial with the central component of the linear receptive field. Both linear and nonlinear mechanisms were caused by an excitatory postsynaptic potential that reversed near $0 \mathrm{mV}$. The nonlinear mechanism depended neither on acetylcholine nor on feedback involving GABA or glycine. Thus the central components of the ganglion cell's linear and nonlinear mechanisms are apparently driven by synapses from the same rectifying bipolar cell.

Key words: intracellular recording; receptive field; spiking amacrine cell; nonlinear subunit; rectification; guinea pig retina
The receptive field of the Y-ganglion cell comprises two excitatory mechanisms. One integrates inputs linearly across a narrow field (i.e., co-spatial with the ganglion cell's dendritic field), and the other integrates inputs nonlinearly across a wide field (Enroth-Cugell and Robson, 1966; Hochstein and Shapley, 1976a,b; Victor et al., 1977). The response of the linear mechanism can be "nulled": when a visual stimulus (such as a grating) is adjusted so that bright and dark cover equal areas, reversing the contrast evokes no response. The response of the nonlinear mechanism cannot be nulled: the cell fires at each contrast reversal, i.e., at twice the stimulus cycle. The nonlinear mechanism resolves a much finer grating (higher spatial frequency) than the linear mechanism, suggesting that the nonlinear mechanism is composed of multiple spatial "subunits" (Hochstein and Shapley, 1976b; Derrington et al., 1979).

The linear mechanism has been attributed to bipolar cells (Hochstein and Shapley, 1976b; Victor et al., 1977; Victor and Shapley, 1979), because their excitatory connections to the ganglion cell are co-spatial with its receptive field center (Freed and Sterling, 1988; Cohen and Sterling, 1992). Furthermore, certain bipolar cells in fish (Toyoda, 1974; Sakai and Naka, 1987a) and primate (Dacey et al., 2000) respond linearly (i.e., do not rectify) and thus could provide linear inputs. The wide-field nonlinear mechanism has been attributed to amacrine cells (Fischer et al., 1975; Hochstein and Shapley, 1976b; Victor et al., 1977; Victor and Shapley, 1979; Derrington et al., 1979), because many types

\footnotetext{
Received May 22, 2001; revised July 13, 2001; accepted July 16, 2001.

This work was supported by National Eye Institute grants F32-EY06850 (J.B.D.), T32-EY07035 (K.Z.), and RO1-EY00828 (P.S.). We thank Drs. Edward Pugh, Michael Freed, Robert Smith, Noga Vardi, and David Calkins for carefully reading and commenting on this manuscript and Sharron Fina for help in preparing this manuscript. We thank Novartis for the generous gift of CGP35348.

Correspondence should be addressed to Jonathan Demb, 123 Anatomy/Chemistry Building, University of Pennsylvania School of Medicine, Philadelphia, PA 19104-6058. E-mail: demb@retina.anatomy.upenn.edu.

Copyright (ㄷ) 2001 Society for Neuroscience 0270-6474/01/217447-08\$15.00/0
}

respond nonlinearly (i.e., rectify; Sakai and Naka, 1987b; Freed et al., 1996; Stafford and Dacey, 1997), and several types extend processes well beyond the ganglion cell's dendritic field (Tauchi and Masland, 1985; Vaney et al., 1988; Dacey, 1989; MacNeil and Masland, 1998). Consistent with this, most synapses on the cat Y-cell are from amacrine cells ( $\sim 76 \%$; Freed and Sterling, 1988; Kolb and Nelson, 1993; Weber and Stanford, 1994). But these attributions have remained uncertain.

For one thing, it has been difficult to grasp how amacrine synapses, which are commonly inhibitory, could generate excitatory nonlinear subunits (Vaney, 1990). For another, recent recordings from bipolar cells in several species-salamander (Burkhardt and Fahey, 1998; Wu et al., 2000), rabbit (Euler and Masland, 2000), and primate (Dacey et al., 2000)—show that certain types express significant rectification. Such bipolar cells might generate the nonlinear mechanism or at least the central component co-spatial with the ganglion cell's dendritic field (Enroth-Cugell and Freeman, 1987). Here we show that the "local" nonlinear mechanism can indeed be separated from the extensive peripheral mechanism, and that when amacrine input is blocked, the central component of the nonlinear mechanism is driven by the same rectifying bipolar synapse that drives the linear mechanism.

\section{MATERIALS AND METHODS}

Intracellular recording. From a guinea pig anesthetized with ketamine and xylazine $(1.0 \mathrm{ml} / \mathrm{kg})$ and nembutal $(3.0 \mathrm{ml} / \mathrm{kg})$, an eye was removed, and the intact retina, including choroid, pigment epithelium, and sclera, was mounted flat on a microscope stage. All procedures were performed in accordance with University of Pennsylvania and National Institutes of Health guidelines. The retina was superfused $(\sim 5 \mathrm{ml} / \mathrm{min})$ with oxygenated $\left(95 \% \mathrm{O}_{2}\right.$ and $5 \% \mathrm{CO}_{2}$ ) Ames medium (Sigma, St. Louis, MO) at $33 \pm 1^{\circ} \mathrm{C}$. Acridine orange $(0.001 \%$; Molecular Probes, Eugene, OR $)$ was added to the superfusate, allowing ganglion cell somata to be identified by fluorescence during brief exposure to near UV light. Large somas $(20-25 \mu \mathrm{m})$ in the visual streak (dorsal and temporal retina, within $4 \mathrm{~mm}$ of the optic disk) were targeted for intracellular recording. Glass elec- 
trodes (tip resistance, 80-200 M $\Omega$ ) included 1\% pyranine (Molecular Probes) and 2\% neurobiotin (Vector Laboratories, Burlingame, CA) in $2 \mathrm{M}$ potassium acetate.

Membrane potential was amplified (IR-283, NeuroData Instruments Corp., Delaware Water Gap, PA), continuously sampled at $2 \mathrm{kHz}$, and stored on a computer (AxoScope software; Axon Instruments, Foster City, CA). Data were analyzed with programs written in Matlab (Mathworks, Natick, MA). Spikes were detected off-line. Membrane potential was analyzed in control conditions after removing spikes computationally (Demb et al., 1999). TTX terminated spiking in $\sim 10 \mathrm{sec}$, leaving just the graded response. To remove high-frequency noise, responses were low-pass-filtered by convolving with a Gaussian filter (SD, 3 msec or 53 $\mathrm{Hz}$ ). Membrane potential responses were averaged over 4-20 repeats of a visual stimulus. The resting potential was determined by averaging the potential over $1 \mathrm{sec}$ before and after each stimulus. Response amplitude was measured by averaging the response over $20 \mathrm{msec}$ around the peak and subtracting the resting potential.

Drugs added to the superfusate included tetrodotoxin (Sigma), D-tubocurarine chloride (Sigma), bicuculline methobromide (Research Biochemicals, Natick, MA), (1,2,5,6-tetrahydropyridine-4yl)-methyphosphinic acid (TPMPA; Sigma), strychnine (Research Biochemicals), and CGP35348 (a gift from Novartis).

After recording, the retina was fixed for $60 \mathrm{~min}$ (4\% paraformaldehyde in $0.1 \mathrm{M}$ phosphate buffer, $\mathrm{pH} 7.4$ ) and then reacted with streptavidinCy3 (Jackson ImmunoResearch, West Grove, PA), mounted in Vectashield (Vector Laboratories, Burlingame, CA), and visualized by fluorescence microscopy as described (Demb et al., 1999). The cell radius was measured as the distance from the soma to the edge of the dendritic field averaged over eight radial directions. Further details were described previously (Demb et al., 1999).

Visual stimulus. The stimulus was displayed on a 1-inch-diameter computer monitor with green phosphor (Lucivid MR1-103; Microbrightfield, Colchester, VT) projected through the top port of the microscope through a $2.5 \times$ objective and focused on the photoreceptor layer. Mean luminance corresponds to $\sim 10^{5}$ isomerizations $\cdot$ cone $^{-1} \cdot \mathrm{sec}^{-1}$. Monitor resolution was $852 \times 480$ pixels with $60 \mathrm{~Hz}$ vertical refresh; stimuli were confined to a square with 430 pixels to a side $(3.7 \mathrm{~mm}$ on the retina). The relationship between gun voltage and monitor intensity was linearized in the software with a look-up table.

Stimuli were spots and square-wave gratings. Except where noted, stimuli were defined in terms of percent Michelson contrast: $100 \times$ $\left(I_{\max }-I_{\min }\right) /\left(I_{\max }+I_{\min }\right)$, where $I_{\max }$ and $I_{\min }$ are the peak and trough intensities. The contrast of fine gratings was corrected on the basis of a measured optical line spread of $40 \mu \mathrm{m}$ (full width at half height; Demb et al., 1999). Stimuli were programmed in Matlab using extensions provided by the high-level Psychophysics Toolbox (Brainard, 1997) and the low-level Video Toolbox (Pelli, 1997).

Model fits. Two models were used to analyze the spot and grating responses in Figure 2. For model 1, the fitted response to spots of increasing diameter (see Fig. $2 A$ ) was based on a difference-of-Gaussians model (Rodieck, 1965), according to the equation:

$$
R_{\text {spot }}(r)=k_{\mathrm{c}}\left(1-\exp \left[-r^{2} / 2 \sigma_{\mathrm{c}, \mathrm{sub}}^{2}\right]\right)-k_{\mathrm{s}}\left(1-\exp \left[-r^{2} / 2 \sigma_{\mathrm{s}}^{2}\right]\right)
$$

The fitted response to gratings of increasing patch diameter (see Fig. 2B) was based on a single Gaussian model, according to the equation:

$$
R_{\text {grating } 1}(r)=k_{\text {sub }}\left(1-\exp \left[-r^{2} / 2 \sigma_{\mathrm{c}, \text { sub }}{ }^{2}\right]\right),
$$

and the fitted response to full-field gratings with increasing mask diameter (see Fig. 2c) was:

$$
R_{\text {grating } 2}(r)=k_{\text {sub }}\left(\exp \left[-r^{2} / 2 \sigma_{\mathrm{c}, \text { sub }}^{2}\right]\right)
$$

where $k_{\mathrm{c}}, k_{\mathrm{s}}$, and $k_{\mathrm{sub}}$ are the peak amplitudes of the linear center, linear surround, and nonlinear subunits, respectively; $\sigma_{\mathrm{c}, \mathrm{sub}}$ and $\sigma_{\mathrm{s}}$ are the SDs of the shared linear center-nonlinear subunits and the linear surround, respectively; and $r$ is the radius of the spot, patch, or mask.

For model 2, the responses to gratings were fit with Equations 2 and 3, except that $\sigma_{\text {sub }}$ was substituted for $\sigma_{\mathrm{c}, \text { sub }}$. Thus, the models differ only in that model 1 forces $\sigma$ to fit both the linear center and the nonlinear subunits, whereas model 2 fits the subunits independently. For both fits, a numerical search determined the parameters, $p$, that minimized (Nelder-Mead simplex method; Matlab) the weighted least squares error function:

$$
X^{2}=\Sigma\left[R_{\mathrm{i}}(p)-R_{\mathrm{i}}\right]^{2} v^{-1}
$$

Where $R_{\mathrm{i}}$ is the measured response to the $i$ th stimulus radius, and $\underline{R}_{\mathrm{i}}$ is the fitted response using $p=\left[k_{\mathrm{c}}, k_{\mathrm{s}}, k_{\mathrm{sub}}, \sigma_{\mathrm{c}, \mathrm{sub}}, \sigma_{\mathrm{s}}\right]$ for model 1 or $p=$ $\left[k_{\text {sub }}, \sigma_{\text {sub }}\right]$ for model 2 . In the denominator, $v$ is response variance. In this way, fitted responses most closely match data points with the lowest variance.

For model 1, the absolute values of the amplitudes $\left(k_{\mathrm{c}}\right.$ and $\left.k_{\mathrm{s}}\right)$ were poorly constrained and would assume unreasonably large values. So we applied the constraint that $k_{\mathrm{c}}$ could not exceed $150 \%$ of the maximum measured spot response. This barely affected the crucial parameter $\sigma$ c,sub, which did not change by $>6 \%$ as this constraint was varied from 110 to $200 \%$ of the maximum response or when there was no constraint.

For model 1, average parameters \pm SEM were as follows: $k_{\mathrm{c}}=15.7 \pm$ $3.2 \mathrm{mV} ; k_{\mathrm{s}}=7.7 \pm 2.0 \mathrm{mV} ; k_{\text {sub }}=4.6 \pm 1.0 \mathrm{mV} ; \sigma_{\mathrm{c}, \text { sub }}=161 \pm 13 \mu \mathrm{m}$; $\sigma_{\mathrm{s}}=334 \pm 33 \mu \mathrm{m} ;$ and $X^{2}=56.7 \pm 12.9$.

For model 2, average parameters were as follows: $k_{\mathrm{sub}}=4.6 \pm 1.0 \mathrm{mV}$; $\sigma_{\text {sub }}=166 \pm 16 \mu \mathrm{m} ;$ and $X^{2}=32.4 \pm 6.8$. Model $2 \sigma_{\text {sub }}$ was only $5.5 \pm$ $5.5 \mu \mathrm{m}$ greater than model $1 \sigma_{\mathrm{c}, \mathrm{sub}}$.

The input-output curve in Figure 5 was described by the following function:

$$
R(I)=\left(a I^{p}\right)\left(I^{p}+I_{50}^{p}\right)^{-1}+b,
$$

where $a$ is peak amplitude, $p$ describes the rise, $I_{50}$ is the semisaturation point, and $b$ is an offset; $I$ is spot intensity (where for OFF cells, bright $=$ 0 and dark $=1$, for ON cells, dark $=0$ and bright $=1$ ), and $R$ is the normalized response amplitude. Fitted parameters (Nelder-Mead simplex method; Matlab) were as follows: OFF cells, $a=2.30 ; p=3.89$; $I_{50}=0.99 ;$ and $b=-0.18$; and ON cells, $a=7.51 ; p=1.57 ; I_{50}=2.27$; and $b=-0.61$.

\section{RESULTS}

\section{Cell classification}

We studied the cellular basis for the nonlinear mechanism by recording intracellularly from ganglion cells in an in vitro preparation of the intact guinea pig retina. Cells were selected as the largest somata (20-25 $\mu \mathrm{m}$ diameter) comprising $\sim 3-5 \%$ of the cell bodies in the ganglion cell layer. Their responses were brisktransient, peaking 50-100 msec after a step change in contrast. All cells showed a center surround organization and a dominant second harmonic response to a high-spatial frequency grating (Hochstein and Shapley, 1976b). When filled with neurobiotin, cells showed a broad (400-800 $\mu \mathrm{m})$, monostratified dendritic field and dye coupling to nearby amacrine cells with long axons (Vaney, 1991; Kao et al., 1999). These ganglion cells in guinea pig retina share morphological and physiological properties with $\mathrm{Y} / \alpha$ cells in other mammalian species; therefore, we refer to them as Y-cells (Enroth-Cugell and Robson, 1966; Hochstein and Shapley, 1976b; Caldwell and Daw, 1978; de Monasterio, 1978; Peichl et al., 1987; Tauchi et al., 1992; Stone and Pinto, 1993).

Conceivably, additional features may allow this population of guinea pig Y-cells to be further subdivided. If so, our conclusions regarding the cellular basis of nonlinear summation would apply to both populations. In fact, our conclusions should generalize to multiple types of ganglion cells, including sluggish cells, because nonlinear spatial summation seems to be a common property of most types (Troy et al., 1989, 1995; Rowe and Cox, 1993; Pu et al., 1994; Demb et al., 1999).

The sample included eight ON-center and $24 \mathrm{OFF}-$ center cells with resting potentials of $-61.6 \pm 1.1 \mathrm{mV}$ (mean $\pm \mathrm{SEM}$ ) and spontaneous firing of $10.0 \pm 2.1$ spikes/sec. Maximum response amplitudes to center spots of appropriate contrast were as large as $22 \mathrm{mV}$ and averaged $10.8 \pm 1.0 \mathrm{mV}$ with $118 \pm 13$ spikes $/ \mathrm{sec}$. The apparent input resistance measured for seven cells ( $3 \mathrm{ON}$ and 4 OFF) was $31 \pm 4.2 \mathrm{M} \Omega$. The cells remained in excellent condition, with large, stable responses for up to $2 \mathrm{hr}$. 
A
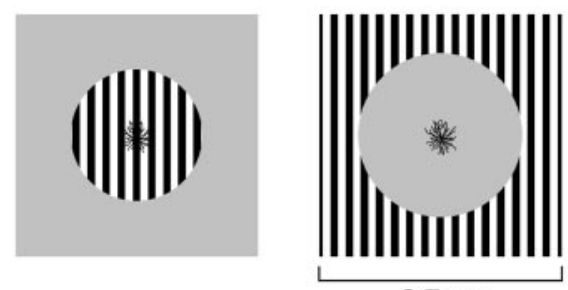

$3.7 \mathrm{~mm}$
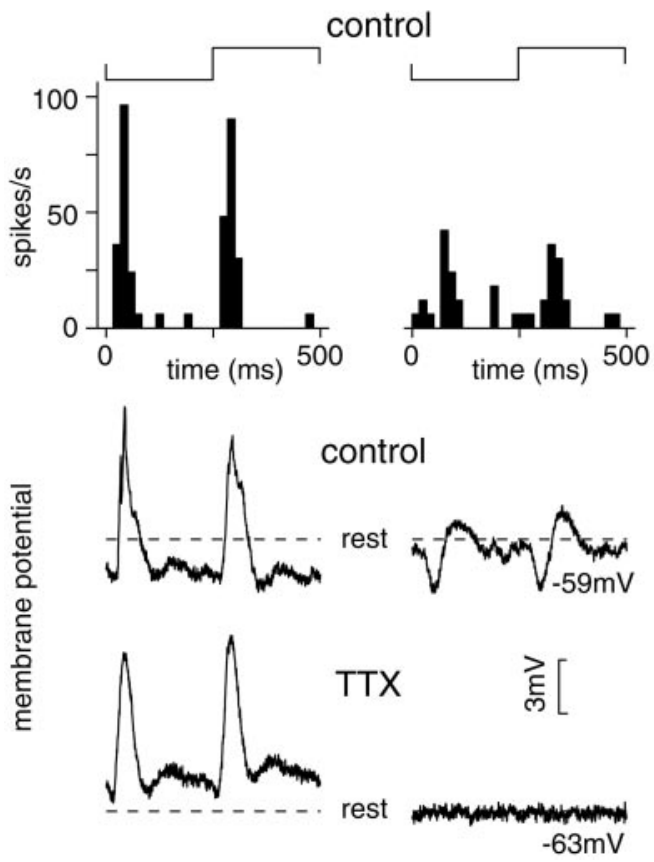

B
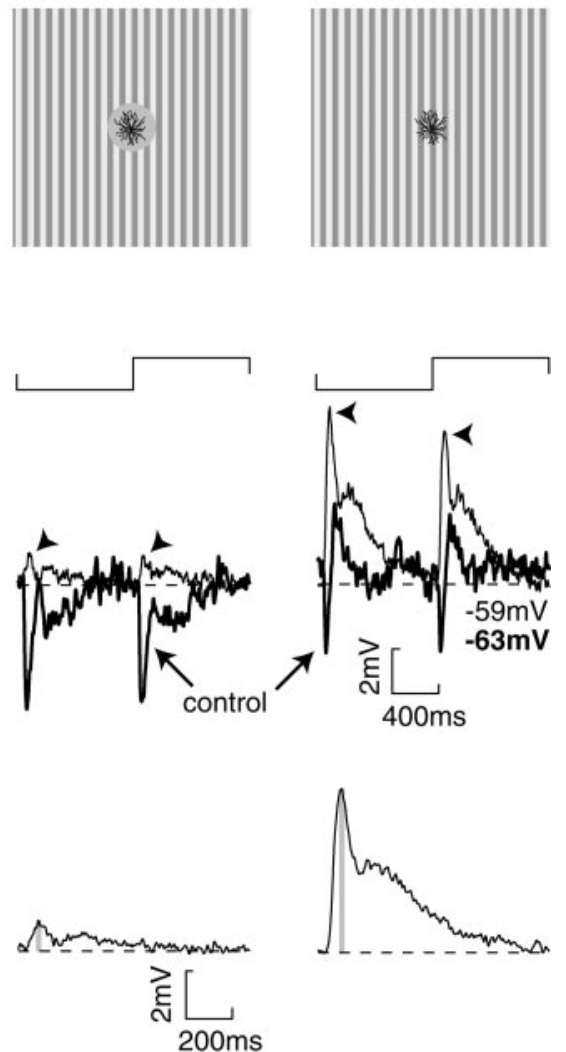

Averaged response to reversal under TTX

Figure 1. The central, excitatory response of the nonlinear mechanism is isolated by tetrodotoxin. $A$, When a fine grating reverses contrast over the dendritic field (left) or over the far periphery (right), a ganglion cell responds with a burst of spikes. To the central grating, the neuron depolarizes at each reversal (spikes clipped as shown by Demb et al., 1999), whereas to the peripheral grating it hyperpolarizes briefly and then depolarizes (middle traces). The response to the central grating is unaffected by TTX $(200 \mathrm{nM})$, but the response to the peripheral grating is abolished (OFF cell; $88 \%$ contrast; reversal at $2 \mathrm{~Hz}$; dashed lines in all figures indicate the resting potential; a cell with a typical dendritic field diameter of $650 \mu \mathrm{m}$ is shown for comparison; bin size for spike poststimulus time histogram, $16.7 \mathrm{msec}$ ). The stimulus trace shows one cycle and describes the luminance time course of half the bars (dark $\rightarrow$ light); the other bars have the opposite time course (light $\rightarrow$ dark). B, A grating covering all but the dendritic field (left) causes a transient and sustained hyperpolarization (thick line). TTX abolished this response except for a small residual depolarization (thin line, arrowheads). The reversal response averaged over both half-cycles is shown below on an expanded time scale. A grating covering the full field (thick line) evoked a biphasic response that includes both response components shown in $A$. TTX removes all but a large depolarizing response (thin line, arrowheads). The gray bar shows the peak depolarization averaged over $20 \mathrm{msec}$ after reversal. This amplitude is plotted in subsequent figures as the response of the nonlinear mechanism (OFF cell; $40 \%$ contrast; reversal at $0.5 \mathrm{~Hz}$ ).

\section{Central component of the nonlinear receptive field is isolated by tetrodotoxin}

When stimulated by a fine, contrast-reversing grating, a cell fired spikes at each reversal (i.e., showed frequency doubling), and this occurred whether the grating was centered over the dendritic tree or confined to the far periphery (Fig. $1 \mathrm{~A}$, top row). However, in the two cases, the membrane potential behaved differently (Fig. $1 A$, middle traces). The central grating hyperpolarized the membrane potential tonically below rest, and each reversal caused a large, transient depolarization. The peripheral grating held the cell near rest, and each reversal caused a transient hyperpolarization followed by a small depolarization (Fig. $1 A$, middle traces). The spike response to the peripheral grating was smaller than that to the central grating and was also slightly delayed $(\sim 20$ msec; Fig. 1 $A$ ).

The delay in the spike response to the peripheral grating is consistent with in vivo recordings (Fischer et al., 1975; Hochstein and Shapley, 1976b; Derrington et al., 1979; Hamasaki and Hanada, 1983). The transient hyperpolarization to the peripheral grating seems consistent with recordings in vivo that show reduced spiking just before the spike burst. This was reported in some transient cells in rabbit retina (Watanabe and Tasaki, 1980), but inhibitory effects were only rarely reported in cat retina (but see Fischer and Kruger, 1974; Passaglia et al., 2001). Either the cat retina lacks an additional inhibitory synapse present in guinea pig and rabbit, or the anesthetics used in cat in vivo recordings affect this component of the response (McIlwain, 1964; Fischer and Kruger, 1974; Hamasaki and Hanada, 1983).

When we added TTX (200 nM) to the bath, the transient depolarizations caused by the central grating were unaltered. However, the tonic hyperpolarization caused by the central grating was reduced, and both the hyperpolarizing and depolarizing responses to the peripheral grating were completely eliminated (Fig. 1 A, bottom traces). This suggests that the tonic hyperpolarization and the response to stimulating the periphery depend on a spiking amacrine cell, whereas the response to a central stimulus depends on local nonspiking input (Demb et al., 1999). 


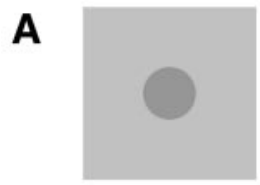

B
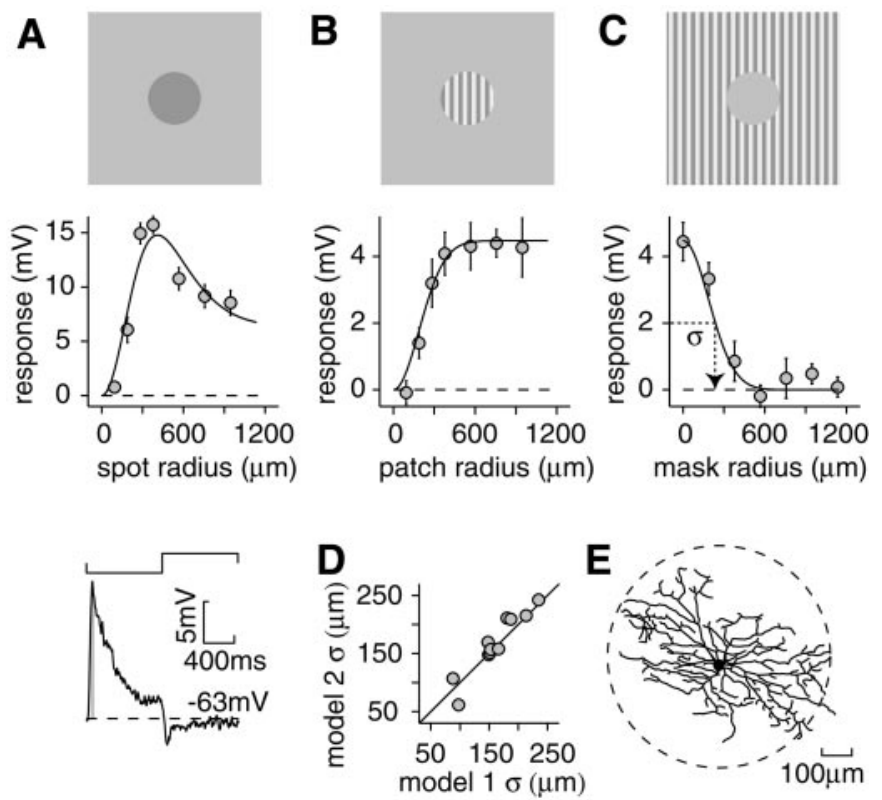

Figure 2. Central nonlinear mechanism isolated by TTX is co-spatial with the receptive field center. $A$, A uniform spot of increasing diameter was used to probe the linear mechanism. The line is a difference-ofGaussians fit. A sample trace is shown below. The amplitude was quantified as the peak depolarization averaged over $20 \mathrm{msec}$ (gray bar). Responses were recorded in presence of TTX. The cell was OFF-center. Error bars indicate SD. B, Circular grating of increasing diameter was used to probe the nonlinear mechanism. The amplitude was quantified as in Figure $1 B$. Points are fitted to a Gaussian. Across 11 cells $(9$ OFF cells and 2 ON cells), grating contrast was 28 or $35 \%$; spot contrast was 20 or 50\%. C, Annular grating of decreasing inner diameter was used to probe the nonlinear mechanism. Points are fitted to a Gaussian; $\sigma$, SD of fitted Gausian. $D, \sigma$ of the fitted Gaussian is plotted for simultaneous fit of grating and spot measurements (model 1) versus independent fit to grating measurements (model 2). The line shows a slope of 1. E, Dendritic field of ganglion cell. The dashed line shows receptive field extent (diameter, $4 \sigma$; model 1).

\section{Central components of the linear and nonlinear mechanisms are co-spatial}

The spatial extent of the TTX-resistant response was measured with various combinations of grating plus a "mask" (a patch or region that remains at mean luminance). A full-field grating with a mask covering the dendritic field evoked a large transient followed by a sustained hyperpolarization (Fig. 1B, left). TTX eliminated the hyperpolarization, revealing a small depolarization. A full-field grating (no mask) evoked a much larger depolarization (Fig. 1B, right), suggesting that the excitatory (TTXresistant) component of the nonlinear mechanism might coincide precisely with the central component of the linear mechanism.

To test this, we added TTX to isolate the central component of the nonlinear mechanism and then determined the space constants of the linear and nonlinear mechanisms. The response of the linear mechanism, probed with a uniform spot, peaked at $\sim 800 \mu \mathrm{m}$ diameter and then declined as the spot invaded the antagonistic "surround" (Fig. $2 A$ ). The response of the nonlinear mechanism, probed with a grating patch, also peaked at $\sim 800 \mu \mathrm{m}$ diameter; however, larger gratings did not antagonize the nonlinear response (Fig. 2B). Consistent with this, the response of the nonlinear mechanism was strongest to a full-field grating and decreased with the expansion of a central mask (Fig. 2C).

To fit the data, we reasoned first that if the linear and nonlinear mechanisms were driven by the same presynaptic neuron (bipolar cell), they would show the same spatial profile (Enroth-Cugell and Robson, 1966; Linsenmeier et al., 1982; Freed et al., 1992). Therefore, we fit responses of both linear and nonlinear mechanisms with the same central Gaussian, subtracting a broad Gaussian for the linear mechanism's surround (model 1; see Materials and Methods). Fits for this model are shown in Figure $2 A-C$, solid lines. Alternatively, we reasoned that if the two mechanisms were driven by different neurons, an independent fit to the nonlinear mechanism (model 2) would require different parameters than the joint fit. The crucial parameter is the SD of the central Gaussian $(\sigma)$ for the linear and nonlinear mechanisms, which describes the space constant of the fit. For model $1, \sigma$ was $161 \pm$ $13 \mu \mathrm{m}$; for model $2, \sigma$ was $166 \pm 16 \mu \mathrm{m}(n=9 \mathrm{OFF}$ and $2 \mathrm{ON})$. $\sigma$ was strongly correlated between the models $(r=0.94 ; p<$ 0.001 ; Fig. 2D). Thus the nonlinear mechanism and the central component of the linear mechanism are spatially identical.

We also compared the extent of the central linear and nonlinear mechanisms with the ganglion cell's dendritic field. Taking the center diameter of the mechanism as $4 \sigma$ (which includes $95 \%$ of its area) (DeVries and Baylor, 1997), the perimeter neatly circumscribed the dendritic field (Fig. $2 E$ ). On average, the diameter of the receptive field was $1.17 \pm 0.12$ times that of the dendritic field $(n=6)$. This ratio is close to previous measurements (Peichl and Wässle, 1983), further suggesting that the same presynaptic neuron provides excitation for both the nonlinear and linear mechanisms.

\section{Central linear and nonlinear mechanisms modulate an excitatory conductance}

If the same synapse mediates the responses to both nonlinear and linear mechanisms, their reversal potentials $\left(E_{\mathrm{rev}}\right)$ should be the same. We tested this, in the presence of TTX, by presenting a grating or a uniform spot while polarizing the ganglion cell with injected current. The response to grating reversal diminished as the cell depolarized and enlarged as it hyperpolarized. The apparent $E_{\text {rev }}$ was $\sim 0 \mathrm{mV}$ (Fig. $3 A$ ). The depolarizing response to the spot behaved similarly, showing the same slope and predicting $E_{\text {rev }}$ as $\sim 0 \mathrm{mV}$. Results were identical for both OFF ( $n=$ $4)$ and ON $(n=3)$ cells. This established that the nonlinear and linear mechanisms are both driven by an EPSP, possibly from the same synapse.

Having observed the EPSP evoked by a central grating under TTX, we wondered how a cell would respond to the same stimulus without the drug. ON cells gave essentially the same monophasic response with a lower amplitude (Fig. $3 C$ ), but OFF cells gave a triphasic response: fast depolarization followed by hyperpolarization and rebound depolarization (Fig. 3C). The two positive phases apparently belong to the primary EPSP isolated under TTX, whereas the negative phase is caused by an IPSP that interrupts the EPSP. This IPSP (Fig. 3C, arrowhead) begins early enough to pull up the apparent reversal potential of the initial peak to near $-40 \mathrm{mV}(n=4)$. Thus under natural conditions, timing of the OFF cell's response to the central grating is sharpened by postsynaptic inhibition from a spiking amacrine cell that is co-spatial with the ganglion cell's dendritic field.

\section{Central nonlinear mechanism responds in the absence of amacrine cell input}

The EPSP (TTX-resistant) evoked by a central grating might be caused either by glutamate from a bipolar cell or by acetylcholine from a "starburst" amacrine cell (Masland et al., 1984), common to all mammalian retinas, including guinea pig (Y.-H. Kao, un- 
A
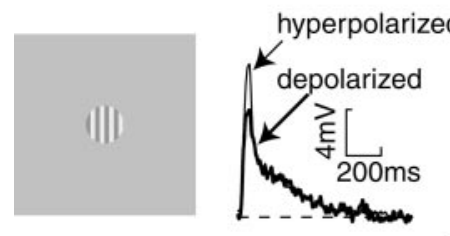

OFF cell

ON cell
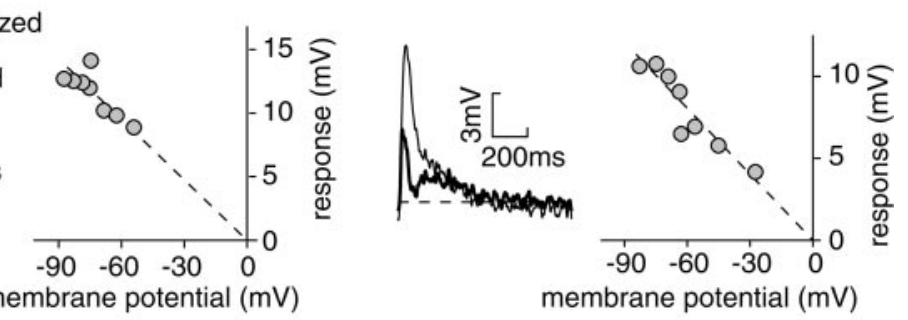

B
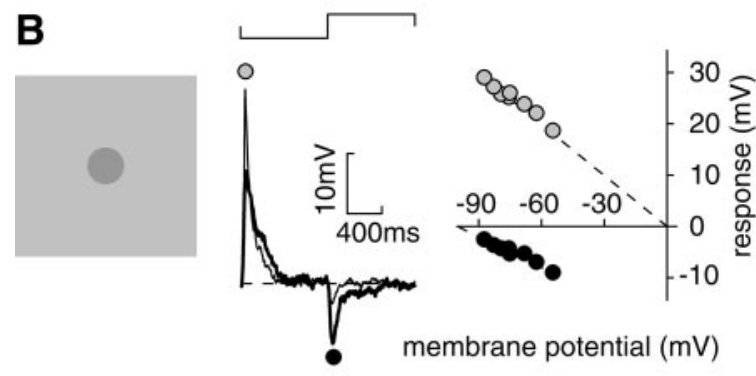

C

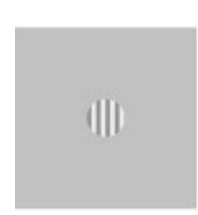

OFF cell

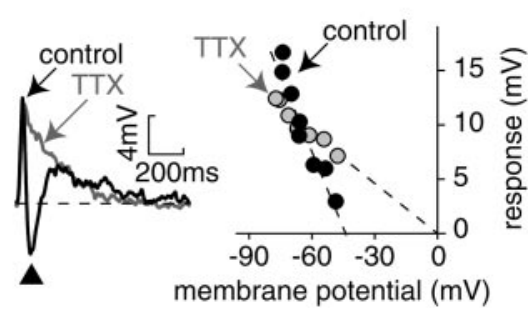

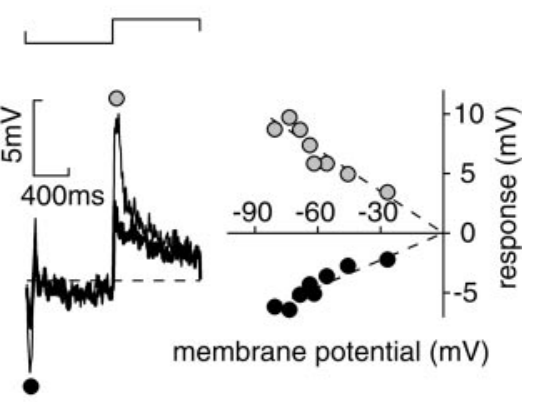

ON cell

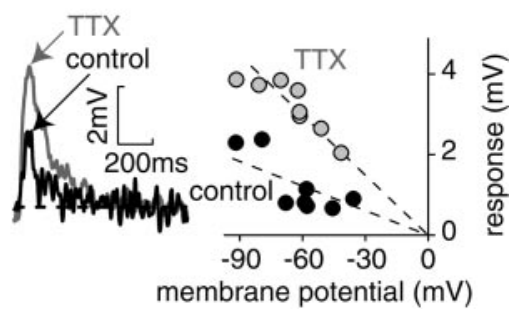

Figure 3. Central nonlinear mechanism modulates an excitatory conductance that reverses near zero. $A$, Grating presented to an OFF and an ON ganglion cell during current injection. Hyperpolarization increased the peak response, and depolarization decreased it. Both plots indicate apparent $E_{\text {rev }}$ of $\sim 0 \mathrm{mV}$. Responses were recorded in the presence of TTX. $B$, Uniform spot presented during current injection. Depolarizing responses at stimulus onset ( gray dots) resembled those to the grating, with an apparent $E_{\text {rev }}$ of $\sim 0 \mathrm{mV}$. However, the hyperpolarizing response in ON and OFF cells was driven by different synaptic mechanisms: ON cell's hyperpolarization to a dark spot (black dots) diminished as the cell was depolarized, with apparent $E_{\text {rev }}$ of $\sim 0 \mathrm{mV}(n=3)$; but OFF cell's hyperpolarization to a bright spot diminished as the cell was hyperpolarized, with an apparent $E_{\text {rev }}$ of approximately $-100 \mathrm{mV}(n=4)$. Thus an ON cell's hyperpolarization is attributable to disfacilitation (presumably presynaptic inhibition); whereas an OFF cell's hyperpolarization is attributable primarily to postsynaptic inhibition. For an OFF cell, the reversal at $-100 \mathrm{mV}$ would arise if direct inhibition $\left(E_{\mathrm{rev}},-80 \mathrm{mV}\right)$ and disfacilitation $\left(E_{\mathrm{rev}}, 0 \mathrm{mV}\right)$ were in a 5:1 ratio. Responses were recorded in the presence of TTX; same cells as in $A$. $C$, Grating presented during current injection in the absence or presence of TTX. With TTX, both cells had an apparent $\mathrm{E}_{\text {rev }}$ of $\sim 0 \mathrm{mV}$ (as in $A$ ). Without TTX, the apparent $E_{\text {rev }}$ of the $\mathrm{OFF}$ cell was approximately $-40 \mathrm{mV}$, suggesting mixed postsynaptic excitation $\left(E_{\text {rev }}, \sim 0 \mathrm{mV}\right)$ and inhibition $\left(\mathrm{E}_{\text {rev }}\right.$, approximately $-80 \mathrm{mV}$ ), but the apparent $E_{\text {rev }}$ of the $\mathrm{ON}$ cell was unchanged at $\sim 0 \mathrm{mV}$.

published observations), and known to contact the Y-cell in cat (Vardi et al., 1989). To test this, we blocked nicotinic acetylcholine receptors with $50 \mu \mathrm{M}$ D-tubocurarine (He and Masland, 1997). This concentration was effective because, in the absence of TTX, it affected other aspects of the light response (data not shown). However, the response to the grating was unaffected across a range of stimulus contrasts (Fig. $4 A ; n=4$ OFF cells and 2 ON cells); therefore the EPSP evoked by a central grating is probably caused by glutamate.

The glutamate release that ultimately causes this EPSP might itself be caused by an amacrine cell modulation of the bipolar terminal. Modulation on this fast time scale would probably involve GABA or glycine, fast transmitters that are ubiquitous among amacrine neurons. To test this, we applied a mixture of antagonists to all the known receptors: $\mathrm{GABA}_{\mathrm{A}}$ (bicuculline, 100 $\mu \mathrm{M}), \mathrm{GABA}_{\mathrm{B}}(\mathrm{CGP}-35348,100 \mu \mathrm{M}), \mathrm{GABA}_{\mathrm{C}}$ (TPMPA, $\left.50 \mu \mathrm{M}\right)$, and glycine receptor (strychnine, $2 \mu \mathrm{M}$ ). This combination of antagonists depolarized the resting potential by nearly $15 \mathrm{mV}$ (from $-60.9 \pm 2.1 \mathrm{mV}$ down to $-46.0 \pm 2.5 \mathrm{mV} ; n=11$ ). Despite the reduced driving force on cations $(\sim 25 \%)$, the response of the nonlinear mechanism persisted and was significantly greater at each of the five highest contrasts (5-80\%; $p<0.05$; Fig. $4 B$ ). After washout, the resting potential returned to a more negative level $(-59.2 \pm 2.7 \mathrm{mV} ; n=10)$. Thus under conditions in which presynaptic inhibition of bipolar terminals is profoundly blocked, the EPSP evoked by a central grating persists.

\section{Instantaneous rectification of bipolar output does not explain the nonlinear mechanism}

Under the hypothesis that the bipolar cell voltage response is purely linear (unrectified; Toyoda, 1974; Sakai and Naka, 1987), we asked whether an instantaneous rectification at the bipolar output could generate the response of the nonlinear mechanism (Enroth-Cugell and Freeman, 1987). For example, if the basal 

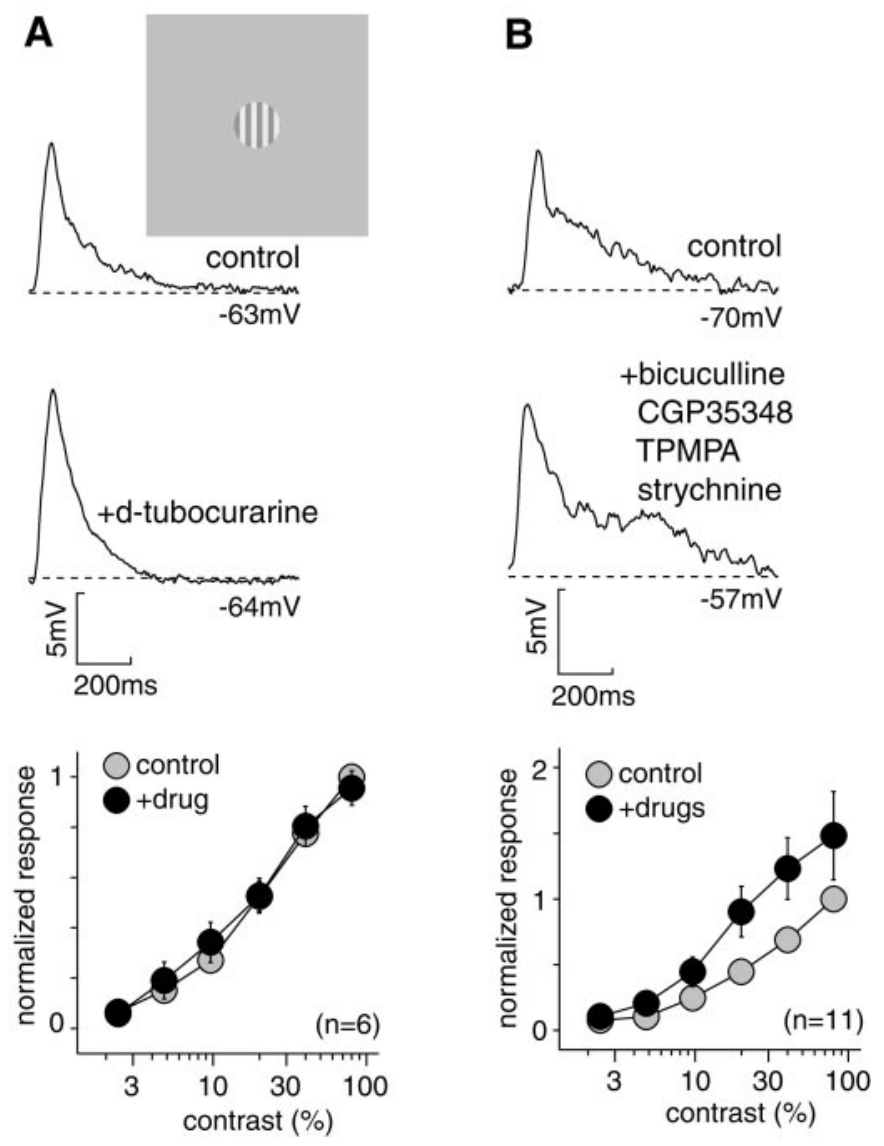

Figure 4. Response of the central nonlinear mechanism does not depend on amacrine cells. $A$, Response evoked by a central grating was isolated with TTX (control). Response was unaffected by D-tubocurarine $(50 \mu \mathrm{M})$ over a wide range of stimulus contrasts (average of 4 OFF cells and 2 ON cells). $B$, Response evoked by a central grating was isolated with TTX (control), followed by a mixture of GABA and glycine antagonists (100 $\mu \mathrm{M}$ bicuculline, $50 \mu \mathrm{M}$ TPMPA, $100 \mu \mathrm{M}$ CGP35348, and $2 \mu \mathrm{M}$ strychnine). The response was not eliminated and actually increased at the highest contrasts (average of 9 OFF cells and 2 ON cells).

rate of transmitter release were low, such a bipolar cell might have a linear voltage response and yet be strongly rectified at the output (because transmitter release cannot go negative). To estimate this output rectification, we recorded the response 40-50 msec after stepping a uniform spot above and below mean luminance (Fig. 5). After $50 \mathrm{msec}$, the depolarizing response saturated presumably because of effects of light adaptation, contrast gain control, or both (Victor, 1987; Walraven et al., 1990).

For OFF cells, the depolarization caused by a full-contrast decrement was approximately fivefold greater than the hyperpolarization caused by a full-contrast increment (Fig. 5). This could be attributable to a rectification at the bipolar cell's release of glutamate, which in OFF cells must be limited in its ability to go negative. Voltage-sensitive channels in the ganglion cell might conceivably contribute to the rectification; however, this contribution would be small, given that voltage-gated $\mathrm{Na}^{+}$channels were blocked (TTX) and that voltage-sensitive $\mathrm{Ca}^{2+}$ channels are not strongly activated in the voltage range of the response (within $\sim 1-20 \mathrm{mV}$ positive of the approximately $-62 \mathrm{mV}$ resting potential).

For ON cells, peak depolarization was less than twofold greater than peak hyperpolarization (i.e., it was nearly linear; Fig. 5). For

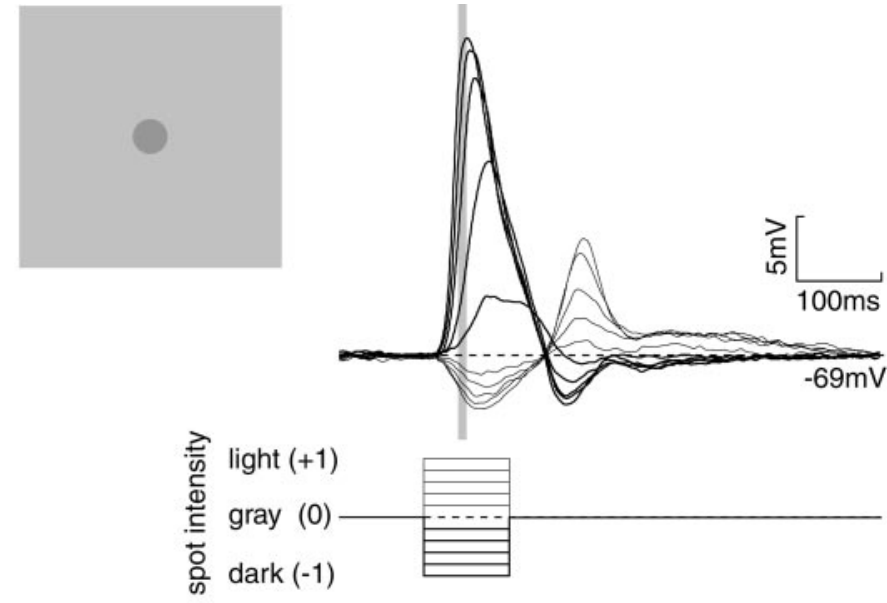

\section{OFF cells}

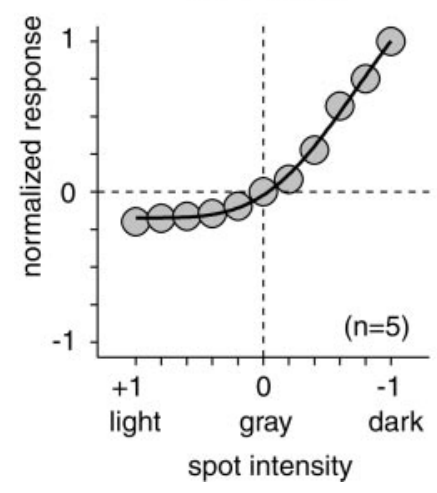

\section{ON cells}

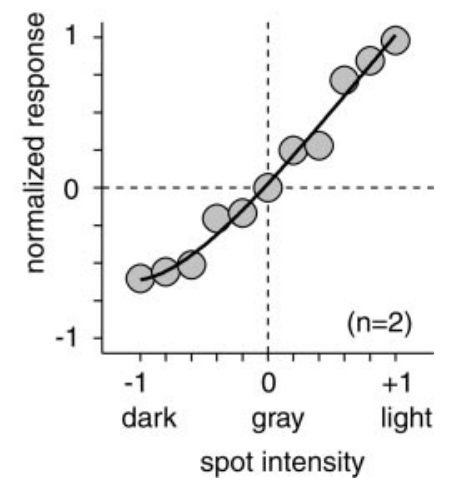

Figure 5. Instantaneous rectification of synaptic input to a ganglion cell. Response to a central spot $(500 \mu \mathrm{m})$ is presented for $100 \mathrm{msec}$ as an increment or decrement from uniform background (OFF cell). Response (averaged over 40-50 msec after stimulus onset; gray bar) was measured for increments up to twice the background (light) and decrements to darkness (dark). Plots show average normalized response for five OFF cells or two ON cells [normalized between maximum response (1) and resting potential (0)]. Data were fit with a sigmoidal response curve with an offset (see Materials and Methods). Responses were recorded in the presence of TTX.

both OFF and ON cells, rectification was essentially absent at contrasts $<20 \%$. Thus, the relationship between bipolar membrane voltage and glutamate release must be essentially linear (unrectified) at low contrast. To explain the response of the nonlinear mechanism, which is proportional to contrast $<20 \%$ (Fig. 4A,B; Hochstein and Shapley, 1976b), there must be an additional rectifying nonlinearity intrinsic to the bipolar cell that functions at low contrast.

\section{DISCUSSION}

We conclude that the linear and nonlinear mechanisms for the central region of the Y-ganglion cell's receptive field can be driven by the same presynaptic circuitry: excitatory input from an array of rectified bipolar cells. OFF bipolar cells provide the excitatory input to the OFF ganglion cell, and ON bipolar cells provide the excitatory input to the ON ganglion cell (Demb et al., 1999). The response of the linear mechanism is generated by homogeneous stimulation of the bipolar array, whereas the response of the nonlinear mechanism is generated by alternate stim- 


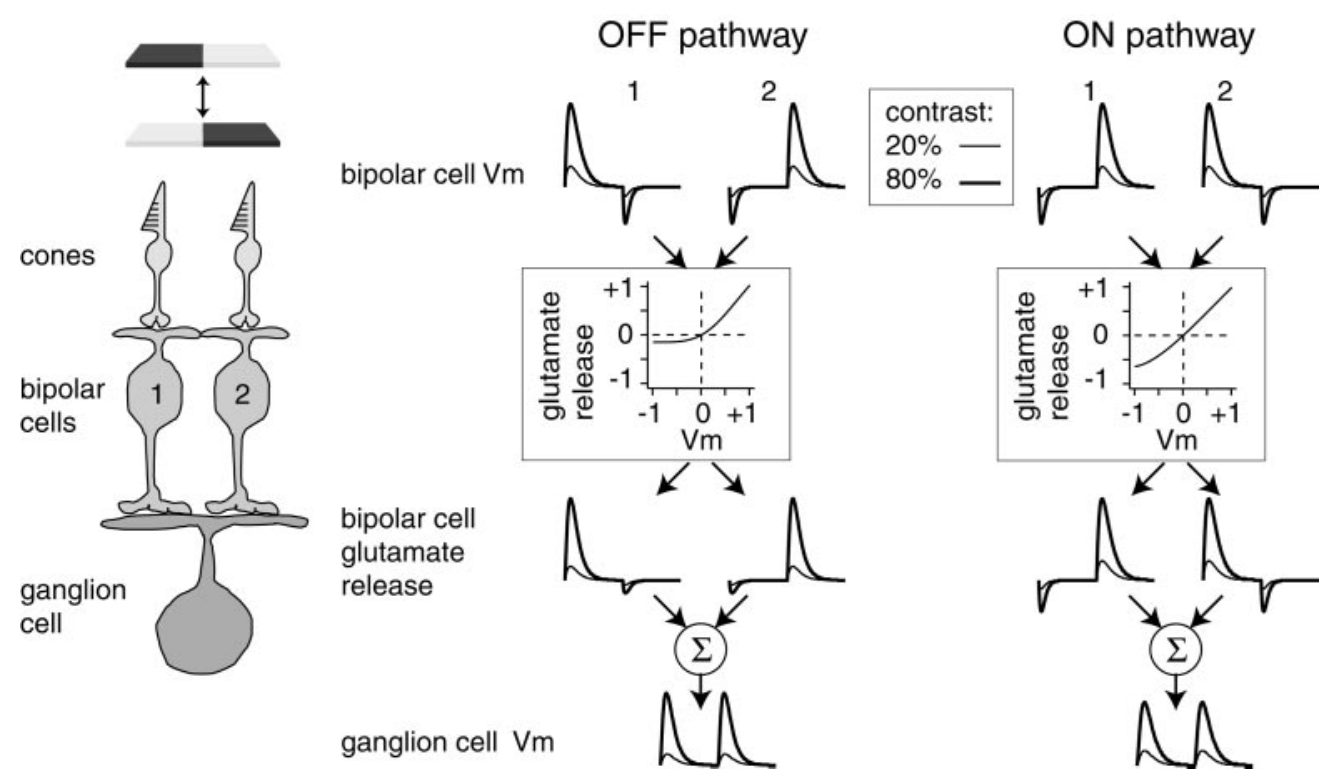

Figure 6. Model for bipolar cell contribution to the excitatory nonlinear mechanism. OFF pathway, When the left bar turns dark, bipolar cell 1 depolarizes and increases transmitter release; when the right bar turns dark, bipolar cell 2 depolarizes and increases transmitter release. Bipolar voltage responses are proportional to contrast but rectified (relatively small negative component), and an additional rectification occurs at the synaptic output, especially at high contrast, because glutamate release can go positive approximately five times as much as it can go negative. The combination of two bipolar outputs, out of phase, is detected at the ganglion cell as the frequency-doubled response. This explains why the central (TTX-resistant) "nonlinear subunit" should have the spatial dimension of a bipolar cell receptive field and why the extent of the subunit field should correspond to the array of bipolar cells that synapse directly on the ganglion cell. A similar circuit is proposed for the ON pathway, except that the output rectification is milder.

ulation of subsets of the array (Fig. 6). Rectification of the Y-cell's subunit and a similar overall model were proposed earlier in general form on the basis of extracellular responses (Hochstein and Shapley, 1976b; Enroth-Cugell and Freeman, 1987).

Our results are consistent with a bipolar cell, presynaptic to the Y-cell, whose voltage response is rectified at all contrasts (Fig. 6). This would provide rectified glutamate release and a response in the ganglion cell's nonlinear mechanism that is proportional to contrast. At high contrast, the output nonlinearity (Fig. 5) would enhance overall bipolar rectification and would cause the response of the ganglion cell's nonlinear mechanism to accelerate rather than saturate (especially in $\mathrm{OFF}$ cells). The saturation actually measured in the response (Fig. 4A,B; Hochstein and Shapley, 1976b) probably arises from contrast gain control, not expressed in the model, which suppresses responses at high contrast (Victor, 1988; Kim and Rieke, 2001). This gain control would need to be stronger in OFF cells to offset the relatively strong effects of their output rectification (Fig. 6), and indeed, gain control is stronger in OFF cells than in $\mathrm{ON}$ cells in salamander (Kim and Rieke, 2001).

Consistent with our model, cone bipolar cells with transient, rectified light responses have been identified (Nelson and Kolb, 1983; Burkhardt and Fahey, 1998; Awatramani and Slaughter, 2000; Dacey et al., 2000; Euler and Masland, 2000; Wu et al., 2000). Furthermore, the $b_{1}$-cell, known to provide the major bipolar input to the cat Y-cell, generates a strong phasic and weak tonic postsynaptic response (Freed and Sterling, 1988; Freed, 2000a). Because most ganglion cell types show strong nonlinear responses, rectified bipolar output may be the norm (Troy et al., 1989, 1995; Rowe and Cox, 1993; Pu et al., 1994; Demb et al., 1999). Properties intrinsic to the bipolar cell must generate this rectification, because it is evident in the absence of amacrine feedback (Fig. 4A,B; Awatramani and Slaughter, 2000; Euler and Masland, 2000). A potential mechanism for OFF bipolar cells would be the ionotropic glutamate receptor on the bipolar cell dendrites, which in certain types enhance transient responses (DeVries, 2000).

What then causes some ganglion cells to be purely linear? It is possibly their input from bipolar types with linear (not rectified) responses. For example, the linear X-cell in cat receives half of its bipolar input from the transient $b_{1}$-cell, but the rest is from two other types $\left(b_{2}\right.$ and $\left.b_{3}\right)$ that generate a strong tonic postsynaptic response and therefore may rectify only weakly (Cohen and Sterling, 1992; Freed, 2000b). If so, their input to the X-cell would tend to obscure the strongly rectified $b_{1}$ input. Consistent with this, the primate midget ganglion cell (linear) collects from a bipolar cell with a linear response (Dacey et al., 2000). Alternatively, X-ganglion cells may achieve their linear properties on the basis of inhibitory inputs that are capable of balancing their excitatory inputs to an extent not present in Y-cells.

What function is served by the Y-cell's nonlinear design? Consider an object with mean luminance that resembles the background on a coarse spatial scale (broader than a cell's receptive field center) but exhibits texture (local contrast) on a fine spatial scale (much narrower than a receptive field center). Motion of this object would be invisible to a cell that summed an array of purely linear elements but would be easily detected by a cell that summed an array of rectifying elements (Baker, 1999). Thus, each bipolar cell's rectified response ensures that its vote will be counted, because it cannot be vetoed by signals of equal magnitude but opposite sign in other parts of the receptive field.

\section{REFERENCES}

Awatramani GB, Slaughter MM (2000) Origin of transient and sustained responses in ganglion cells of the retina. J Neurosci 20:7087-7095.

Baker Jr CL (1999) Central neural mechanisms for detecting secondorder motion. Curr Opin Neurobiol 9:461-466.

Brainard DH (1997) The psychophysics toolbox. Spat Vis 10:433-436.

Burkhardt DA, Fahey PK (1998) Contrast enhancement and distributed encoding by bipolar cells in the retina. J Neurophysiol 80:1070-1081. 
Caldwell JH, Daw NW (1978) New properties of rabbit retinal ganglion cells. J Physiol (Lond) 276:257-276.

Cohen E, Sterling P (1992) Parallel circuits from cones to the on-beta ganglion cell. Eur J Neurosci 4:506-520.

Dacey DM (1989) Axon-bearing amacrine cells of the macaque monkey retina. J Comp Neurol 284:275-293.

Dacey D, Packer OS, Diller L, Brainard D, Peterson B, Lee B (2000) Center surround receptive field structure of cone bipolar cells in primate retina. Vision Res 40:1801-1811.

Demb JB, Haarsma L, Freed MA, Sterling P (1999) Functional circuitry of the retinal ganglion cell's nonlinear receptive field. J Neurosci 19:9756-9767.

de Monasterio FM (1978) Properties of concentrically organized X and Y ganglion cells of macaque retina. J Neurophysiol 41:1394-1417.

Derrington AM, Lennie PM, Wright J (1979) The mechanism of peripherally evoked responses in retinal ganglion cells. J Physiol (Lond) 289:299-310.

DeVries SH (2000) Bipolar cells use kainate and AMPA receptors to filter visual information into separate channels. Neuron 28:847-856.

DeVries SH, Baylor DA (1997) Mosaic arrangement of ganglion cell receptive fields in rabbit retina. J Neurophysiol 78:2048-2060.

Enroth-Cugell C, Freeman AW (1987) The receptive-field spatial structure of cat retinal Y cells. J Physiol (Lond) 384:49-79.

Enroth-Cugell C, Robson JG (1966) The contrast sensitivity of retinal ganglion cells of the cat. J Physiol (Lond) 187:517-552.

Euler T, Masland RH (2000) Light-evoked responses of bipolar cells in a mammalian retina. J Neurophysiol 83:1817-1829.

Fischer B, Kruger J (1974) The shift-effect in the cat's lateral geniculate neurons. Exp Brain Res 21:225-227.

Fischer B, Kruger J, Droll W (1975) Quantitative aspects of the shifteffect in cat retinal ganglion cells. Brain Res 83:391-403.

Freed MA (2000a) Rate of quantal excitation to a retinal ganglion cell evoked by sensory input. J Neurophysiol 83:2956-2966.

Freed MA (2000b) Parallel cone bipolar pathways to a ganglion cell use different rates and amplitudes of quantal excitation. $\mathrm{J}$ Neurosci 20:3956-3963

Freed MA, Sterling P (1988) The ON-alpha ganglion cell of the cat retina and its presynaptic cell types. J Neurosci 8:2303-2320.

Freed MA, Smith RG, Sterling P (1992) Computational model of the on-alpha ganglion cell receptive field based on bipolar circuitry. Proc Natl Acad Sci USA 89:236-240.

Freed MA, Pflug R, Kolb H, Nelson R (1996) ON-OFF amacrine cells in cat retina. J Comp Neurol 364:556-566.

Hamasaki DI, Hanada I (1983) A comparison of the shift response of Xand Y-cells in the cat's retina. Exp Brain Res 50:117-124.

He S, Masland RH (1997) Retinal direction selectivity after targeted laser ablation of starburst amacrine cells. Nature 389:378-382.

Hochstein S, Shapley RM (1976a) Quantitative analysis of retinal ganglion cell classifications. J Physiol (Lond) 262:237-264.

Hochstein S, Shapley RM (1976b) Linear and nonlinear spatial subunits in Y cat retinal ganglion cells. J Physiol (Lond) 262:265-284.

Kao Y-H, Demb JB, Haarsma L, Johnson M, Sterling P (1999) An axon-bearing amacrine cell tracer coupled to the OFF Y ganglion cell. Invest Ophthalmol Vis Sci 40:S813.

Kim KJ, Rieke F (2001) Temporal contrast adaptation in the input and output signals of salamander retinal ganglion cells. J Neurosci 21:287-299

Kolb H, Nelson R (1993) OFF-alpha and OFF-beta ganglion cells in cat retina: II. Neural circuitry as revealed by electron microscopy of HRP stains. J Comp Neurol 329:85-110.

Linsenmeier RA, Frishman LJ, Jakiela HG, Enroth-Cugell C (1982) Receptive field properties of $\mathrm{X}$ and $\mathrm{Y}$ cells in the cat retina derived from contrast sensitivity measurements. Vision Res 22:1173-1183.

MacNeil MA, Masland RH (1998) Extreme diversity among amacrine cells: implications for function. Neuron 20:971-982.

Masland RH, Mills JW, Hayden SA (1984) Acetylcholine-synthesizing amacrine cells: identification and selective staining by using radioautography and fluorescent markers. Proc R Soc Lond B Biol Sci 223:79-100.

McIlwain JT (1964) Receptive fields of optic tract axons and lateral geniculate cells; peripheral extent and barbiturate sensitivity. J Neurophysiol 27:1154-1173.

Nelson R, Kolb H (1983) Synaptic patterns and response properties of bipolar and ganglion cells in the cat retina. Vision Res 23:1183-1195.
Passaglia CL, Enroth-Cugell C, Troy JB (2001) Effects of remote stimulation on the mean firing rate of cat retinal ganglion cells. J Neurosci 21:5794-5803.

Peichl L, Wässle H (1983) The structural correlate of the receptive field centre of alpha ganglion cells in the cat retina. J Physiol (Lond) 341:309-324.

Peichl L, Ott H, Boycott BB (1987) Alpha ganglion cells in mammalian retinae. Proc R Soc Lond B Biol Sci 231:169-197.

Pelli DG (1997) The VideoToolbox software for visual psychophysics: transforming numbers into movies. Spat Vis 10:437-442.

Pu M, Berson D, Pan T (1994) Structure and function of retinal ganglion cells innervating the cat's geniculate wing: an in vitro study. J Neurosci 14:4338-4358.

Rodieck RW (1965) Quantitative analysis of cat retinal ganglion cell response to visual stimuli. Vision Res 5:583-601.

Rowe MH, Cox JF (1993) Spatial receptive-field structure of cat retinal W cells. Vis Neurosci 10:765-769.

Sakai HM, Naka K (1987a) Signal transmission in the catfish retina. IV. Transmission to ganglion cells. J Neurophysiol 58:1307-1328.

Sakai HM, Naka K (1987b) Signal transmission in the catfish retina. V. Sensitivity and circuit. J Neurophysiol 58:1329-1350.

Stafford DK, Dacey D (1997) Physiology of the A1 amacrine: a spiking, axon-bearing interneuron of the macaque monkey retina. Vis Neurosci 14:507-522.

Stone C, Pinto LH (1993) Response properties of ganglion cells in the isolated mouse retina. Vis Neurosci 10:31-39.

Tauchi M, Masland RH (1985) Local order among the dendrites of an amacrine cell population. J Neurosci 5:2494-2501.

Tauchi M, Morigiwa K, Fukuda Y (1992) Morphological comparisons between outer and inner ramifying alpha cells of the albino rat retina. Exp Brain Res 88:67-77.

Toyoda J (1974) Frequency characteristics of retinal neurons in the carp. J Gen Physiol 63:214-234.

Troy JB, Einstein G, Schuurmans RP, Robson JG, Enroth-Cugell C (1989) Responses to sinusoidal gratings of two types of very nonlinear retinal ganglion cells of cat. Vis Neurosci 3:213-223.

Troy JB, Schweitzer-Tong DE, Enroth-Cugell C (1995) Receptive-field properties of $\mathrm{Q}$ retinal ganglion cells of the cat. Vis Neurosci 12:285-300.

Vaney DI (1990) The mosaic of amacrine cells in the mammalian retina. In: Progress in retinal research (Osborne NN, Chader G, eds), pp 49-100. Oxford, Pergamon.

Vaney DI (1991) Many diverse types of retinal neurons show tracer coupling when injected with biocytin or neurobiotin. Neurosci Lett 125:187-190.

Vaney DI, Peichl L, Boycott BB (1988) Neurofibrillar long-range amacrine cells in mammalian retinae. Proc $\mathrm{R}$ Soc Lond B Biol Sci 235:203-219.

Vardi N, Masarachia PJ, Sterling P (1989) Structure of the starburst amacrine network and its association with alpha ganglion cells. J Comp Neurol 288:601-611.

Victor JD (1987) The dynamics of the cat retinal X cell centre. J Physiol (Lond) 386:219-246.

Victor JD (1988) The dynamics of the cat retinal Y cell subunit. J Physiol (Lond) 405:289-320.

Victor JD, Shapley RM (1979) The nonlinear pathway of Y ganglion cells in the cat retina. J Gen Physiol 74:671-689.

Victor JD, Shapley RM, Knight BW (1977) Nonlinear analysis of cat retinal ganglion cells in the frequency domain. Proc Natl Acad Sci USA 74:3068-3072.

Walraven J, Enroth-Cugell C, Hood DC, MacLeod DIA, Schnapf JL (1990) The control of visual sensitivity: receptoral and postreceptoral processes. In: The neurophysiological foundations of visual perception (Spillman L, Werner J, eds), pp 53-101. New York: Academic.

Watanabe J, Tasaki K (1980) Shift-effect in the rabbit retinal ganglion cells. Brain Res 181:198-201.

Weber AJ, Stanford LR (1994) Synaptology of physiologically identified ganglion cells in the cat retina: a comparison of retinal $\mathrm{X}$ - and Y-cells. J Comp Neurol 343:483-499.

Wu SM, Gao F, Maple BR (2000) Functional architecture of synapses in the inner retina: segregation of visual signals by stratification of bipolar cell axon terminals. J Neurosci 20:4462-4470. 